\title{
Linkage between fishers' foraging, market and fish stocks density: Examples from some North Sea fisheries
}

\author{
Paul Marchal ${ }^{a}$, Jan-Jaap Poos ${ }^{b}$ and Floor Quirijns ${ }^{b}$ \\ aIFREMER, Channel and North Sea Fisheries Department, 150 Quai Gambetta, BP 699, 62321 \\ Boulogne s/mer, France \\ ${ }^{\mathrm{b}}$ IMARES, P.O. Box 68, 1970 AB IJmuiden, The Netherlands \\ *: Corresponding author : paul.marchal@ifremer.fr
}

\begin{abstract}
:
This study has investigated some properties of fishermen's foraging, using Levy flights theory. The case studies examined were a selection of North Sea Dutch and French vessels, for which catch and effort data were collected on a haul-by-haul basis. Foraging behavior could reasonably be represented by a Levy flight process, characterized by an exponentiation factor $\mu$, for both fleets. The properties of fishers' foraging were further investigated for the Dutch fleet using time series analysis. Optimal foraging was found with $\mu=1.5$, suggesting a slow recovery dynamics of the stocks being harvested. Efficient foraging led to high value per unit effort, while the knowledge of fishing grounds with high stock density is shown to increase foraging efficiency in the short-term future. Only marginal correlations could be found between $\mu$ and the other explanatory variables considered (fish prices and fishing effort).
\end{abstract}

Keywords: Fleet behavior; Levy flights; Fishing effort; Foraging; Haul-by-haul data 


\section{Introduction}

The effectiveness of fisheries management relies heavily on the understanding of a number of key processes including fishers behavior, development of vessel and gear technology and the impact exerted by fishing units on the ecosystem. Changes in fishers' behavior have been demonstrated in a number a studies, with regards to shifts in either the spatial distribution of fishing effort (Rijnsdorp et al., 1998; Rijnsdorp et al., 2000a), or métiers choices (Holley and Marchal, 2004; Ulrich and Andersen, 2004), or discarding practices (Stratoudakis et al., 1998). The effect of fishers' behavior on catch rates has been investigated by, e.g., Abrahams and Healey (1990), Hilborn (1985), Sampson (1991), Gillis (1999), Salthaug and AAnes (2003), Marchal et al. (2006). Other studies have examined the different factors which could influence fishers' decisions. The factors investigated included the fishers' perception of stock density (Hilborn and Ledbetter, 1979, Gillis et al., 1993; Hutton et al., 2004), management regulations (Pascoe et al., 2001; Marchal et al., 2002), competition between fishing vessels (Gillis and Peterman, 1998; Rijnsdorp et al., 2000b) and fish prices (Holley and Marchal, 2004). These processes have to some extent been integrated into prototype simulation models, which have been developed to represent the dynamics of fishers' behavior (Dorn, 1998; Holland, 2000; Salas et al., 2004). Despite these advances, a substantial amount of work still has to be carried out to get a more comprehensive understanding of the complexity of fleet dynamics, and to be able to include the key processes into an operational bioeconomic model, which could be used routinely by fisheries managers.

One of the areas where progress could be made is in the definition of appropriate indices describing fishing tactics. Consistent with Laloë and Samba (1991) and Laurec et al. (1991), fishing tactics may be defined as the sequence of decisions taken at sea by a skipper at the scale of the fishing trip. One major sequence of decisions taken by skippers is the spatial allocation of fishing effort, which itself reflects the spatial trajectory pursued by a fishing vessel during a trip. A number of studies have investigated fishers' spatial tactics through analogies with animals' foraging behavior (e.g. Gillis et al., 1993; Gillis, 2003; Bertrand, 2005).

Spatially explicit methods and indices have been developed to characterize and summarise the properties of foragers' behavior, as reflected by their spatial trajectories and distributions. Bertrand (2005) proposed a generic review and classification of these methods and indices.

With regards analyses of spatial distributions, Bertrand (2005) identified indices derived from gravity center and inertia of data points (Murawski and Finn, 1988), relationship between mean and variance (Rijnsdorp et al., 1998), variance per sampling square (Plotnick et al., 1996), spatial auto-correlation (Petitgas, 1993), neighborhood properties of data points (Ripley, 1976; Salthaug and AAnes, 2003), distance measurements (Perry, 1995), home ranges (Crecco and Overholt, 1990), frequency analyses (Ripley, 1978), fractal theory (Mandelbrot, 1977), overlap measurements (Grünbaum, 2002).

With regards analyses of spatial trajectories, Bertrand (2005) identified two main categories. First, the "Lagrangian" approach focuses on individual trajectories. These may be characterized through, (i) basic statistics of movement, including foraging duration, feeding location, distance to the coast (e.g. Sims and Quayle, 1998; Staniland et al., 2004), (ii) tortuosity/straightness indices which may be used to estimate the complexity and the fractal dimensions of spatial trajectories (e.g. Bowne and White, 2004; Nams, 2005), (iii) random walks (Bovet and Benhamou, 1988) and, (iv) Individual Based Modelling (Beecham, 2001). 
Second, the Eulerian approach is designed to investigate the movements of populations, which are essentially characterized by three key processes: advection, diffusion and reaction. These processes have been modeled in a number of ecological papers (e.g. Skellam, 1951).

Analyses of spatial trajectories are particularly well suited to investigate behavioral dynamics. To be performed, these analyses require fine-scale information on the location of the foragers under investigation. Such data may be derived from satellite VMS (Vessel Monitoring System) records and also direct observations on-board, which are becoming increasingly accessible to fishery science in general, and fishers' behavior studies in particular.

General statistics (i) and indices of tortuosity/straightness (ii) are useful to describe the properties of spatial trajectories. However, neither approach builds on a conceptual framework that would allow contrasting observed trajectories, as reflected by (i) and (ii), with some hypothetical trajectory drawn from the ecological theory. Individual Based Modelling (IBM) approaches (iv) clearly build in mechanistic concepts. However, these concepts need to be modeled before being included in the overall IBM framework.

Random walks (iii) describe trajectories through a deterministic and a stochastic components, and these are believed to be useful tools to model and describe behavioral dynamics (Bertrand, 2005). Random walks may be categorized as "Brownian", "biased and/or correlated" and "Levy type”. The Levy-flight theory has recently been borrowed by ecologists from the physical sciences to characterize the spatial distribution of predators or foragers and also to determine optimal search strategies for foragers looking for sparsely and randomly distributed targets (Viswanathan et al., 1996; Viswanathan et al., 2002). In short, Lévy flight are characterized by many short moves and few large displacements. This theory has been successfully tested on different foraging animals such as bumble bees, Bombus trifasciatus (Viswanathan et al., 1999), wandering albatrosses, Diomedea exulans (Viswanathan et al., 1996), reindeers, Rangifer tarandus tarandus (Maarell et al., 2002), jackals, Canis adustus (Atkinson et al., 2002), grey seals, Halichoerus grypus (Austin et al., 2004), spider monkeys, Ateles geoffroyi (Ramos-Fernández et al., 2004). More recently, this approach has been applied to describe the fishers' searching behavior in the Peruvian anchovy (Engraulis ringens) fishery (Bertrand et al., 2005). Bertrand et al. (2005) however did not investigate the determinants of searching behavior for that fishery.

The scope of the present paper is, (i) to characterize the foraging efficiency of fishing vessels, belonging to different fleets, based on the Levy flight theory but also, (ii) to get better insights into the factors associated to fishers' foraging. This approach was applied on two case studies, for which fine scale, haul by haul, catch and effort data could be made available: the Dutch large beam-trawlers targeting sole (Solea solea) and plaice (Pleuronectes platessa), and the French large otter-trawlers targeting saithe (Pollachius virens).

\section{Data}

Haul-by-haul catch and effort have been collated and collected in the course of the TECTAC research project for one Dutch and one French fleets (Marchal, unpublished). These data have been used for the purpose of this study. We make here the assumption that the trajectory of fishing vessels between two consecutive hauls is a straight line. The different fleets and data sets are described below.

\subsection{Dutch fleet}

The Dutch fleet investigated includes large beam-trawlers (>300 HP). The target species of this fleet are plaice and sole and the fishery takes place throughout the North Sea. Beam trawl vessels usually fish from Sunday night until Friday morning. They fish throughout day and night and need about 15 minutes for emptying the nets and setting the nets back into the 
water. During the weekend most of the vessels are in the harbor, although a small group of vessels sometimes go out to sea for a 2-weeks trip. Haul-by-haul logbook data are compiled, containing landing, mid positions and timing of each haul (Table 1). Fishing grounds of the Dutch fleet under investigation are situated throughout the North Sea, but outside of the 12miles zone, where these vessels are not allowed to fish (Figure 1). Most of the effort registered in the haul-by-haul data is located in the southern part of the North Sea. Catch and effort data was available for the period 1995-2003 (Figure 2).

2.2. French fleet

The French fleet investigated includes large otter-trawlers ( $>40 \mathrm{~m})$ registered in Northern France. This fleet is sub-divided into two groups of vessels. The first group of vessels operates mostly in the Northern North Sea and targets saithe. The second group operates off Western Scotland (sub-area VI) and in the Celtic Sea (sub-area VII), and targets deep-water species. Only the haul-by-haul catch and effort data provided by the first group of vessels were collected. However, these data were collected for most of the fishing trips operated by these vessels (Table 1). Fishing grounds of the Northern France otter-trawlers are mainly situated in the Northern North Sea around the Shetland Islands (Figure 1). Catch and effort data could be made available for the period 2003-2004 (Figure 3).

2.3. Fish prices

Monthly fish prices were made available from sale slips for sole and plaice, harvested by the Dutch fleet (Figure 2), and for saithe, harvested by the French fleet (Figure 3).

\section{Methods}

\subsection{Quantifying the foraging efficiency of the fishing fleets}

The concepts underlying this analysis are based on the Lévy flights theory, and they may be found in Viswanathan et al. (1996, 1999, 2002). Compared to Brownian movements, in which the length of steps is constant, Lévy flights show spatial scale invariance in the length of constituent steps and temporal scale invariance in the duration of intervals between steps. (Shlesinger et al., 1993). Lévy flights generate trajectories with many short moves and few large displacements. Lévy flights are characterized by a distribution function

$$
P\left(l_{i}\right) \sim l_{i}^{-\mu}
$$

with $1<\mu \leq 3$, and where $l_{i}$ is the flight length, which in the present analysis is interpreted as the distance covered by a fishing vessel between two fishing operations. The gaussian is the stable distribution for the special case $\mu>3$, while values $\mu \leq 1$ do not correspond to probability distributions that can be normalized. Value $\mu=1$ corresponds to a ballistic trajectory. Value $\mu=3$ corresponds to a Brownian trajectory.

To estimate the parameter $\mu$, one proceeds as follows. For each fleet and each month, the frequency distribution of the distance between hauls $(l)$ is calculated. The bin size (w) used to group the continuous variable $l$ into discrete classes is that suggested by Scott (1979):

$\mathrm{w}=3.5 \mathrm{sn}^{-1 / 3}$

with s standard deviation of the sample of size $n$. Log-frequency is then plotted against $\log (l)$, using the arithmetic mean of the bins. A regression is then fitted through the data points, the slope of which is $-\mu$. Monthly time series of $\mu$ and of the $95 \%$ confidence intervals derived from the regression are then produced for each fleet. 


\subsection{Optimal foraging (searching) efficency}

Viswanathan et al. (1999) investigated, through both theoretical considerations and numeric simulations, the value of the Lévy flight exponent $\mu$ corresponding to optimal searching efficiency. Two main assumptions underlie this investigation. First, prey aggregations, referred as target sites, are randomly distributed. Second foragers are assumed to move randomly from one target site to another when they cannot detect preys in their neighborhood. Viswanatan et al. (1999) examined different types of foraging scenarios (destructive or not), and also different distributions of target sites (sparse or not). Target sites are sparsely distributed when the mean free path of the forager between successive target inter-sites distance exceeds the distance of prey detection within a target site.

When target sites are sparsely distributed and when foraging is non-destructive (i.e. target sites may be visited several times), optimal searching was found with $\mu=2$. When target sites are not sparsely distributed, searching efficiency may be considered independent of $\mu$. When target sites are sparsely distributed but when foraging is destructive (i.e. target sites may be visited only once), optimal searching is found with ballistic moves $(\mu=1)$. Depending on the delay time during which a previously visited target site becomes unavailable, the type of foraging may lie between destructive and non-destructive. Raposo et al. (2003) showed that the optimal $\mu$ depends on that delay time and is included in the range 1.0-2.0.

For the case studies investigated in this paper, the optimal value of $\mu$ is unknown. However, it may not be unreasonable to consider that optimal strategies are rewarded by the highest value per unit effort (VPUE). This optimum $\left(\mu^{*}\right)$ was approached by examining the relationship between VPUE and $\mu$. We then calculated a new index $\Delta \mu$ defined as the distance to optimum:

$\Delta \mu=\left|\mu-\mu^{*}\right|$

The lower $\Delta \mu$, and the more successful foraging.

\subsection{Factors associated to foraging}

The time structure of $\Delta \mu$ and of the different input series were first examined using an autocorrelation function.

Second, monthly time series of $\Delta \mu$ (response series) were contrasted with the input series of fishing effort, value per unit of effort (VPUE) and fish prices, using cross-correlation functions. When input series are auto-correlated, which is usually the case, the direct crosscorrelation between the input and response series gives a misleading indication of the relationship linking these series. Pre-whitening was then applied to the series as follows. First, an adequate ARMA model was estimated for the input series. Second, both series were then filtered using that model. Finally, the cross-correlation function was then calculated between the filtered response series and the filtered input series.

When $\Delta \mu$ is close to 0 , foraging is expected to be optimal, so VPUE should be higher than average. VPUE could also be seen as an indicator of fishers' perception of stock density. It may be anticipated that fishers adapt their fishing strategy as a result of the yield they achieved in past month(s). Therefore, past VPUE may have an influence on their foraging behavior, and hence on $\Delta \mu$. As ratios often have inadequate statistical properties VPUE were log-transformed before being used in subsequent analyses.

Past fishing efforts could have an effect on past stock abundance, which could affect current foraging efficiency. Conversely, one could imagine that foraging efficiency could have an influence on future fishing activities. The relation between the foraging efficiency and fishing effort was therefore investigated. 
Price fluctuations make a target species attractive or not. It is therefore possible that $\Delta \mu$ will depend on market conditions, as reflected by fish prices.

Finally, although management is likely to have an impact on fishers' behavior, it has not been integrated in our analysis. The fleets under investigation have been constrained both by the plaice and sole TACs (Total Allowable Catches) and also by effort limitations taken in the North Sea to restore the cod (Gadus morhua) stock. However, these management measures are regularly updated on an annual basis while time series of $\Delta \mu$ are calculated monthly. This difference in time resolution makes it impractical to contrast the time series of $\Delta \mu$ with annual management.

Cross-correlation functions were used to quantify the linkage between $\Delta \mu$, catch rates, value per unit effort, fishing effort and fish prices, at different time lags.

\subsection{Implementation}

Foraging efficiency was estimated for both the Dutch and the French fleets being examined. The analysis of factors affecting foraging by means of auto- or cross-correlations could only be carried out with time series of reasonable length. Consequently, this analysis was applied only to the Dutch fleet fishing in the North Sea.

The different analyses detailed above have been implemented using mainly SAS/STAT (1999) and SAS/ETS (1999).

\section{Results}

4.1. Quantifying the foraging efficiency of the fishing fleets

Two examples of the log-log regression between frequencies and inter-haul distances are given on Figures 4a (Dutch fleet) and 4b (French fleet). The slope of the log-log regression between frequencies and inter-haul distances was always significantly different from zero ( $\mathrm{p}<$ 0.01), except for 6 data points (i.e. months) for the Dutch fleet (January 1995, June and August 1998, April 2000, July 2002, September 2003) (Figure 5a), and 3 data points for the French fleet (October, November and December 2003) (Figure 5b). For these data points were the slope was not significantly different from zero, fishing activity was at low level (Figures 3a and 3b). $\mu$ was estimated as minus the slope of the regression, when significantly different from $0(\mathrm{p}<0.05)$. For the Dutch fleet, the average value of the foraging coefficient $\mu$ fluctuates without trends in the range 1.0-1.9 except in April 2000, April 2002, May 2002, August 2002 (Figure 5a). For these four data points, fishing activity was at low level (Figures 3a). For the French fleet, the average value of the foraging coefficient $\mu$ fluctuates within 1.21.8 .

Finally, we find that $1<\mu \leq 3$ in most of cases, suggesting that the distance covered by fishing vessels between two fishing operations may reasonably be represented by a Levy flight process for both fleets being investigated.

\subsection{Optimal foraging (searching) efficency}

Figure 6 suggests that optimal foraging for the Dutch fleet is found around 1.5. This value corresponds to the average value of $\mu$ for that fleet (Figure 3a). $\mu^{*}$ will be set at 1.5 for the Dutch fleet in subsequent analyses.

\subsection{Factors affecting foraging}

The auto-correlation of $\Delta \mu$ did not reveal any particular time structure at any lag (Figure 7a). The input time series however were subject to substantial auto-correlations, which were mainly due correlations between consecutive observations and also seasonal patterns (Figures 
7b-d). Table 2 shows the ARMA models used to pre-whiten the time series before calculating the cross-correlation functions.

Figures 8a, 8b and 8d indicate that there are significant but marginal correlations between fish prices and $\Delta \mu$ (at lags 3 and 7 for plaice, at lags -12 and 2 for sole), and also between fishing effort and $\Delta \mu$ (at lags 5 and 12). However, these appear to be more of an artifact than an underlying signal.

Consider the correlation between $\Delta \mu$ and Log(VPUE) (Figure 8c). The negative correlation found at lag 0 could be anticipated, as the highest VPUE would be expected when foraging efficiency is closest to optimal. The high negative correlation found at lag 4 may indicate that past VPUE, which could be interpreted as a proxy of the fisher's perception of stock density, may have a positive impact on foraging efficiency. More data would be needed to confirm this finding.

\section{Discussion}

This study explored a rather novel index of fishing tactics. This index, which is derived from the ecological theory (Levy flights), has been used in previous studies to characterise the foraging behavior of animals and, more recently, fishers (Bertrand et al. 2005). To be calculated, this index required precise GPS positions of fishing hauls and corresponding catches be available. Such data could be made available for Dutch beam-trawlers and, to a more limited extent, French large trawlers registered in Northern France. The conclusions of this investigation are limited by the fact that they build on a limited number of case studies. Despite this limitation, there are lessons to be learnt from this approach.

The analysis of foraging efficiency suggested that, for both the Dutch and the French fleets under investigation, the foraging strategy may reasonably be represented by a Levy flight process. This results bears out the outcomes of similar analyses applied to the Peruvian pelagic fishery (Bertrand et al., 2005). This study confirms that the foraging behavior of human beings is comparable to that of other animals including albatrosses, bees, jackals, reindeers, spider monkeys to which a similar approach has been applied (e.g. Viswanathan et al., 1996; Viswanathan et al., 1999; Atkinson et al., 2002; Maarell et al., 2002; Viswanathan et al., 2002; Ramos-Fernández et al., 2004).

The range of value found for the foraging parameter $\mu$ needs further comments, also in contrast with the values found in the studies mentioned above. In this study, $\mu$ was found in the range 1.0-2.0 for both the French and the Dutch fleets. The values of $\mu$ found in animal behavior studies were generally found around 2 (albatros, bee, reindeer, jackal, spider monkey). Investigating the foraging behavior of fishers harvesting anchovy in Peru, Bertrand et al. (2005) found that $\mu$ was also around 2. Austin et al. (2004), who investigated the foraging behavior of grey seals found out that only some animals pursued a foraging strategy consistent with a Lévy flight. For these animals, $\mu$ was in the range 1.0-1.5.

We can propose one hypothesis to explain our results in relation to those from other studies. This is to assume that in all case studies presented above, foragers have pursued optimal searching strategies, and that the value found for $\mu$ may reflect how quickly target sites have been able to recover.

For non-destructive foraging, Viswanathan (1999) indicated that $\mu=2$ could be the optimal value characterizing a Lévy flight search. Although this may require further investigation, it may not be unreasonable to assume that albatrosses, bees, reindeers, jackals and spider monkeys pursue a non-destructive foraging strategy, allowing revisiting target sites, either 
because of light exploitation, or because of the quick recovery dynamics of their prey. The quick recovery dynamics of the Peruvian anchovy stock (Bertrand et al., 2004) could also explain why target sites may be revisited.

Raposo et al. (2003) showed that when there is a high delay time during which a previously visited target site becomes unavailable, the optimal $\mu$ depends on that delay time and is included in the range 1.0-2.0. This situation may apply to the foraging dynamics of grey seals. Grey seals are top marine predators, and may have significant top-down impact on ecosystem functioning (Bowen, 1997). The exploitation of flatfish stocks in the North Sea may be bounded by similar constraints. Flatfish stocks in the North Sea are believed to be exploited beyond biological safe limits by fisheries, and have not showed evidence of quick recovery dynamics in recent years (ICES, 2005).

Overall, despite differences in the values taken by the foraging parameter $\mu$, there are arguments to support the view that foraging strategies have been close to optimal in all the examples presented above, including the North Sea flatfish fishery investigated in this study. The fact than $\mu$ is well below 2 for the North Sea flatfish case study may then indicate a slow recovery dynamics of the harvested fish stocks.

Alternatively, we may question some of the key assumptions underlying this approach, and particularly the search for the optimal value of the foraging parameter $\mu$. First, it has been assumed that target sites are randomly distributed. In fact, flatfish aggregations are likely to be determined by their habitat and may not be randomly distributed. Second it has been assumed that foragers may move randomly from one target site to another when they cannot detect preys in their neighborhood. This assumption may also be violated because of the experience gained by skippers, allowing them to travel directly towards known fishing grounds. These restrictions are in fact not specific to this study but also apply to all the studies where foraging behavior has been investigated using Lévy flight analysis. A logical followup to the present study would then be to investigate how sensitive optimal foraging is to the underlying assumptions.

High value per unit effort was achieved when foraging was close to optimal, as expected. The link between past values per unit effort and current foraging efficiency may result from value per unit efforts reflecting the fishers' perception of stocks density. Thus, high catch rates could be expected to benefit the skippers' experience in terms of knowledge of fishing grounds with high stock density. It may then be anticipated that this gain in experience could contribute to increase foraging efficiency in the short-term future (i.e. four months later for our case study). It could be investigated whether these results are confirmed by applying this approach to other fisheries.

There were no clear correlations between foraging efficiency and the other potential determinants investigated (fishing effort and fish prices). This may indicate that the relationship between these variables is of a more complex nature, requiring a different approach. For instance, Holley and Marchal (2004) have shown that the decline of saithe prices over the period 1999-2003 have made saithe fishing gradually less attractive over that period. However, fish prices provide only partial information on the economic incentives driving fishermen's decisions. In particular, a number of economic drivers including subsidies, operational or fixed costs are thought to affect fishers' decisions, but such information could not be made available for that study.

This study examined some of the key processes underlying fishers' behavior. The impact of annual management could not be investigated given the size of the time series being analysed. With longer time series (which are expected to become available via VMS data recording and 
observers on-board) the span of these series will increase. Management would then become a key factor to be examined along with economic parameters and skippers' perception of fish density. Longer time series will also permit to carry out modeling exercises (e.g. ARIMA, Kalman filtering), which may help forecasting fleets' behavior in the short-term future.

\section{Acknowledgements}

This work was funded through the TECTAC project by the European Union (DG Fisheries, study no. QLRT-2001-01291). This support is gratefully acknowledged. We are also indebted to skippers and vessels owners for providing data, without which this investigation could not have been carried out.

\section{References}

Abrahams, M.V., and Healey, M.C., 1990. Variation in the competitive abilities of fishermen and its influence on the spatial distribution of the British Columbia Salmon Troll Fleet. Can. J. Fish. Aquat. Sci. 47 , 1116-1121.

Atkinson, R.P.D., Rhodes, C.J., Macdonald, D.W., and Anderson, R.M., 2002. Scale-free dynamics in the movement patterns of jackals. Oikos 98, 134-140.

Austin, D., Bowen, W.D., and McMillan, J.I., 2004. Intraspecific variation in movement patterns: modeling individual behaviour in a large marine predator. Oikos 105, 15-30.

Beecham, J.A., 2001. Towards a cognitive niche: divergent foraging strategies resulting from limited cognitive ability of foraging herbivores in a spatially complex environment. Biosystems 61, 55-68.

Bertrand, A., Segura, M., Gutiérrez, M., and Vásquez, L., 2004. From small-scale habitat loopholes to decadal cycles: a habitat-based hypothesis explaining fluctuation in pelagic fish populations off Peru. Fish Fish. 5, 296-316.

Bertrand, S., 2005. Analyse comparée des dynamiques spatiales des poisons et des pêcheurs : mouvements et distributions dans la pêcherie d'anchois (Engraulis ringens) du Pérou. Ph.D. thesis, Ecole Nationale Supérieure Agronomique de Rennes, 2005-26 / H-64, 193 pp.

Bertrand, S., Burgos J.M., Gerlotto, F., and Atiquipa, J., 2005. Lévy trajectories of Peruvian purse-seiners as an indicator of the spatial distribution of anchovy (Engraulis ringens). ICES J. Mar. Sci. 62, 477-482.

Bovet, P., and Benhamou, S., 1988. Spatial analysis of animals' movements using a correlated random walk model. J. Theor. Biol. 131, 419-433.

Bowen, W.D., 1997. Role of marine mammals in aquatic ecosystems. Mar. Ecol. Prog. Ser. 158, 267-274.

Bowne, D.R., and White, H.R., 2004. Searching strategy of the painted turtle Chrysemys picta across spatial scales. Anim. Behav. 68, 1401-1409.

Crecco, V., and Overholtz, W.J., 1990. Causes of density-dependent catchability for Georges Bank haddock (Melanogrammus aeglefinus). Can. J. Fish. Aquat. Sci. 47, 385-394.

Dorn, M.W., 1998. Fine-scale fishing strategies of factory trawlers in a midwater trawl fishery for Pacific hake (Merluccius productus). Can. J. Fish. Aquat. Sci. 55, 180-198.

Gillis, D.M., 1999. Behavioral inferences from regulatory observer data: catch rate variation in the Scotian Shelf silver hake (Merluccius bilinearis) fishery. Can. J. Fish. Aquat. Sci. 56, 288-296.

Gillis, D.M., 2003. Ideal free distributions in fleet dynamics: a behavioral perspective on vessel movement in fisheries analysis. Can. J. Zool. 81, 177-187.

Gillis, D.M., and Peterman, R.M., 1998. Implications of interference among fishing vessels and the ideal free distribution to the interpretation of CPUE. Can. J. Fish. Aquat. Sci. 55, 37-46. 
Gillis, D.M., Peterman, R.M., and Tyler, A.V., 1993. Movement dynamics in a fishery: application of the ideal free distribution to spatial allocation of effort. Can. J. Fish. Aquat. Sci. 50, 323-333.

Grünbaum, D., 2002. Predicting availability to consumers of spatially and temporally variable resources. Hydrobiol. 480, 175-191.

Hilborn, R., 1985. Fleet dynamics and individual variation : why some people catch more fish than others. Can. J. Fish. Aquat. Sci. 42, 2-13.

Hilborn, R., and Ledbetter, M., 1979. Analysis of the British Columbia salmon purse-seine fleet: dynamics of movement. J. Fish. Res. Board Can. 36, 384-391.

Holland, D.S., 2000. A bio-economic model of marine sanctuaries on Georges Bank. Can. J. Fish. Aquat. Sci. 57, 1307-1319.

Holley, J.-F., and Marchal P., 2004. Fishing strategy development under changing conditions: examples from the French offshore fleet fishing in the North Atlantic. ICES J. Mar. Sci. 61, 1410-1431.

Hutton, T., Mardle, S., Pascoe, S., and Clark, R.A., 2004. Modelling fishing location choice within miwed fisheries: English North Sea beam trawlers in 2000 and 2001. ICES J. Mar. Sci. 61, 1443-1452.

ICES, 2005. Report of the ICES Advisory Committee on Fishery Management, Advisory Committee on the Marine Environment and Advisory Committees on Ecosystems (2005). ICES Advice, Vol. 1-11, 1418 pp.

Laloë, F., and Samba, 1991. A simulation model of artisanal fisheries of Senegal. ICES Mar. Sci. Symp. 193, 281-286.

Laurec, A., Biseau, A., and Charuau, A., 1991. Modeling technical interactions. ICES Mar. Sci. Symp. 193, 225-236.

Maarell, A., Ball, J.P., and Hofgaard, A., 2002. Foraging and movement paths of female reindeer: insights from fractal analysis, correlated random walks, and Lévy flights. Can. J. Zool. 80, 854-865.

Mandelbrot, B.B., 1977. Fractals, form, chance and dimension. Freeman W.H. and Company, San Francisco.

Marchal, P., Andersen, B., Bromley, D., Iriondo, A., Mahévas, S., Quirijns, F., Rackham, B., Santurtún, M., Tien, N., and Ulrich, C., 2006. Improving the definition of fishing effort for important European fleets, by accounting for the skipper effect. Can. J. Fish. Aquat. Sci. 63, 510-533.

Marchal, P., Ulrich, C., and Pastoors, M., 2002. Area-based management and fishing efficiency. Aquat. Liv. Resour. 15, 73-85.

Murawski, S.A., and Finn, J.T., 1988. Biological bases for mixed-species fisheries: species co-distribution in relation to environmental and biotic variables. Can. J. Fish. Aquat. Sci. 45, 1720-1735.

Nams, V.O., 2005. Using animal movement paths to measure response to spatial scale. Oecol. 143, 179-188.

Pascoe, S., Andersen, J.L., and de Wilde, J.W., 2001. The impact of management regulation on the technical efficiency of vessels in the Dutch beam trawl fishery. Eur. Rev. Agric. Econ. 28, 187-206.

Perry, J.N., 1995. Spatial analysis by distance indices. J. Anim. Ecol. 64, 303-314.

Petitgas, P., 1993. Geostatistics for fish stock assessments: a review and an acoustic application. ICES J. Mar. Sci. 50, 285-298.

Plotnick, R.E., Gardner, R.H., Hargrove, W.W., Prestegaard, K., and Perlmutter, M., 1996. Lacunarity analysis. A general technique for the analysis of spatial patterns. Physical Review E 53, 5461-5468. 
Ramos-Fernández, G., Mateos, J.L., Miramontes, O., Cocho, G., Larralde, H., and AyalaOrozco B., 2004. Lévy walks patterns in the foraging movements of spider monkeys (Ateles geoffroyi). Behav. Ecol. Sociobiol. 55, 223-230.

Raposo, E.P., Buldyrev, S.V., da Luz, M.G.E., Santos, M.C., Stanley, H.E., and Viswanathan, G.M., 2003. Dtnamical robustness of Lévy search strategies. Physical Review Letters 91, 1-4.

Rijnsdorp, A.D., Buys, A.M., Storbeck, F., and Visser, E.G., 1998. Micro-scale distribution of beam trawl effort in the southern North Sea between 1993 and 1996 in relation to the trawling frequency of the sea bed and the impact on benthic organisms. ICES J. Mar. Sci. 55 , 403-419.

Rijnsdorp, A.D., Dol, W., Hoyer, M., and Pastoors, M.A., 2000a. Effects of fishing power and competitive interactions among vessels on the effort allocation on the trip level of the Dutch beam trawl fleet. ICES J. Mar. Sci. 57 , 927-937.

Rijnsdorp, A.D., van Mourik Broekman, P.L., and Visser, E.G., 2000b. Competitive interactions among beam trawlers exploiting local patches of flatfish in the North Sea. ICES J. Mar. Sci. 57 , 894-902.

Ripley, B.D., 1976. The second-order analysis of stationary point processes. J. Appl. Probability 13, 255-266.

Ripley, B.D., 1978. Spectral analysis and the analysis of pattern in plant communities. J. Ecol. 66, 965-981.

Salas, S.; Sumaila, U.R. and Pitcher, T., 2004. Short-term decisions of small-scale fishers selecting alternative target species: a choice model. Can. J. Fish. Aquat. Sci. 61, 374383.

Salthaug, A., and AAnes, S., 2003. Catchability and the spatial distribution of fishing vessels. Can. J. Fish. Aquat. Sci. 60, 259-268.

Sampson, D.B., 1991. Fishing tactics and fish abundance and their influence on catch rates. ICES J. Mar. Sci. 48, 291-301.

Scott, D.W., 1979. On optimal and data-based histograms. Biom. 66, 605-610.

SAS/ETS, 1999. SAS Institute Inc., SAS/STAT User's Guide, Version 8, Cary, NC, 1519 pp.

SAS/STAT, 1999. SAS Institute Inc., SAS/STAT User's Guide, Version 8, Cary, NC, 3884 pp.

Shlesinger, M.F., Zaslavsky, G.M., and Klafter, J., 1993. Strange kinetics. Nat. 363, 31-37.

Sims, D.W., and Quayle, V.A., 1998. Selective foraging behaviour of basking sharks on zooplankton in a small-scale front. Nat. 393, 460-464.

Skellam, J.G., 1951. Random dispersal in theoretical populations. Biometrika 38, 196-218.

Staniland, I.J., Reid, K., and Boyd, I.L., 2004. Comparing individual and spatial influences on foraging behaviour in Antarctic fur seals Arctocephalus gazella. Mar. Ecol. Prog. Ser. 275, 263-274.

Stratoudakis, Y., Fryer, R.J., and Cook, R.M., 1998. Discarding practices for commercial gadoids in the North Sea. Can. J. Fish. Aquat. Sci. 55, 1632-1644.

Ulrich, C., and Andersen, B.S., 2004. Dynamics of fisheries, and the flexibility of vessel activity in Denmark between 1989 and 2001. ICES J. Mar. Sci. 61, 308-322.

Viswanathan, G.M., Afasynev, V., Buldyrev, S.V., Murphy, E.J., Prince, P.A., and Stanley, H.E., 1996. Lévy flight search patterns of wandering albatrosses. Nature 381, 413415.

Viswanathan, G.M., Bartumeaus, F., Buldyrev, S.V., Catalan, J., Fulco, U.L., Havlin, S., da Luz, M.G.E., Lyra, M.L., Raposo, E.P., Stanley, H.E., 2002. Lévy flight random searches in biological phenomena. Phys. 314, 208-213.

Viswanathan, G.M., Buldyrev, S.V., Havlin, S., da Luz, M.G.E., Raposo, E.P., and Stanley, H.E., 1999. Optimizing the success of random searches. Nature 401, 911-914. 


\section{Figure captions}

Figure 1. Map of the investigated ICES (International Council for the Exploration of the Sea) areas, including the spatial distribution of fishing effort in 2003 for the sample of Dutch large beam-trawlers and French large otter-trawlers, for which haul by haul catch and effort data were available.

Figure 2. Case study: Dutch large beam-trawlers. Time series of, (a) sole (Solea solea) and plaice (Pleuronectes platessa) prices (euros/kg), (b) fishing effort (hours fished), (c) log-transformed plaice and sole catch rates (kg per hours fished), (d) log-transformed value per unit effort (euros per hours fished).

Figure 3. Case study: French large otter-trawlers registered in Northern France. Time series of, (a) saithe (Pollachius virens) prices (euros/kg), (b) fishing effort (hours fished), (c) log-transformed saithe catch rates (kg per hours fished).

Figure 4. Regression, on a log-scale, of the frequency distribution of the distance covered by a fishing vessel between two consecutive hauls ( $\mathrm{Y}$ axis) versus that distance (X axis). The slope of the regression is $-\mu$. Examples (one month and one fishing vessel) drawn from (a) the Dutch fleet and (b) the French fleet.

Figure 5. Time series of the foraging parameter $\mu$ (black dot), including 95\% confidence limits intervals (dotted lines), as calculated for (a) the Dutch large beam trawlers and (b) the French large otter trawlers.

Figure 6. Case study: Dutch large beam-trawlers. Relationship between the foraging parameter $\mu$ and Value per Unit Effort VPUE (euros per hour fished), including 95\% confidence limits intervals (dotted lines).

Figure 7. Case study: Dutch large beam-trawlers. Auto-correlation (needles) of, (a) distance to optimal foraging efficiency $\Delta \mu$, (b) plaice (Pleuronectes platessa) prices, (c) sole (Solea solea) prices, (d) log-transformed value per unit effort and, (e) fishing effort. 
The standard error based on the hypothesis that the process generating the time series is a pure moving average is shown as dotted lines.

Figure 8. Case study: Dutch large beam-trawlers. Cross-correlation (needles) of the distance to optimal foraging efficiency $\Delta \mu$ with, (a) plaice (Pleuronectes platessa) prices, (b) sole (Solea solea) prices, (c) log-transformed value per unit effort and, (d) fishing effort. The standard error under the assumption that two time series are uncorrelated is shown as dotted lines. 
[Marchal et al. - Figure 1]

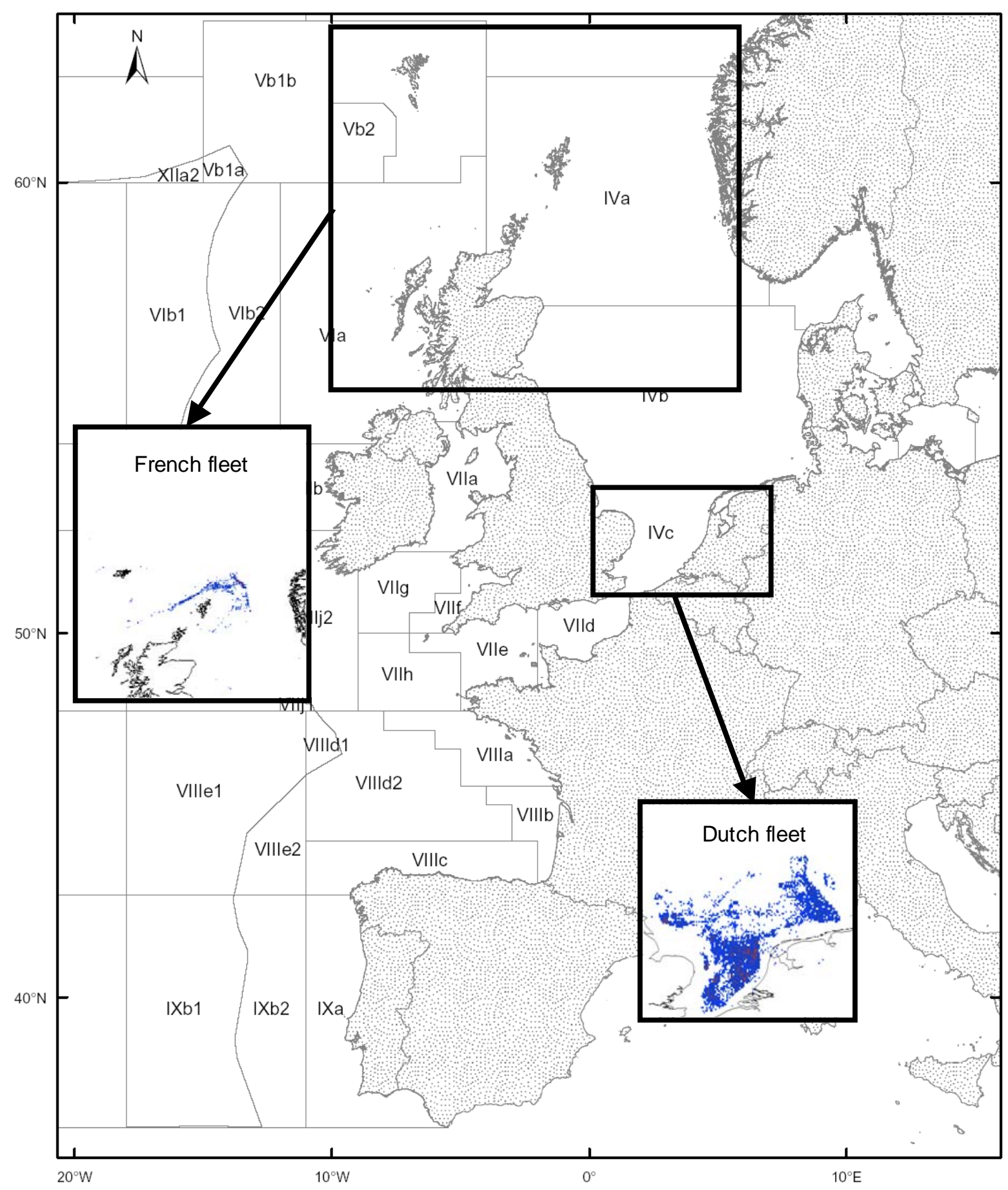


[Marchal et al. - Figure 2]

(a)

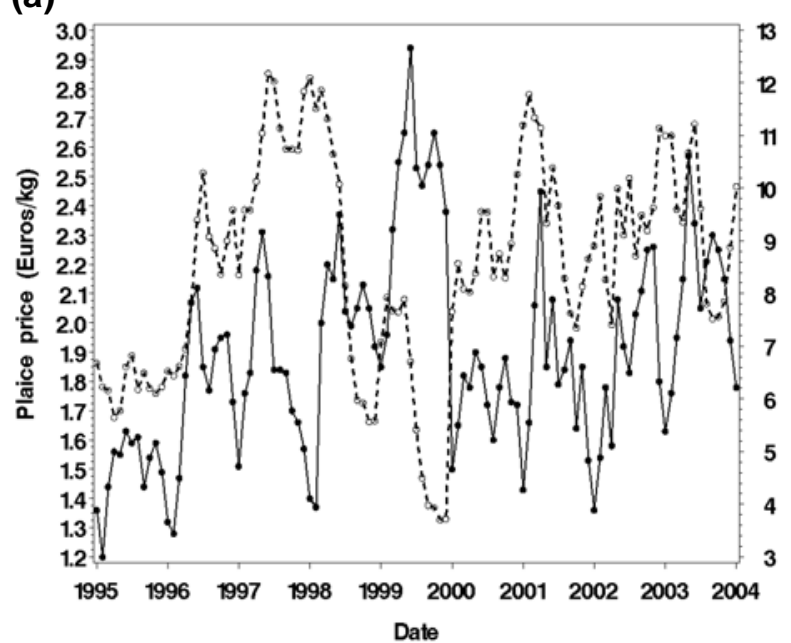

(b) 80

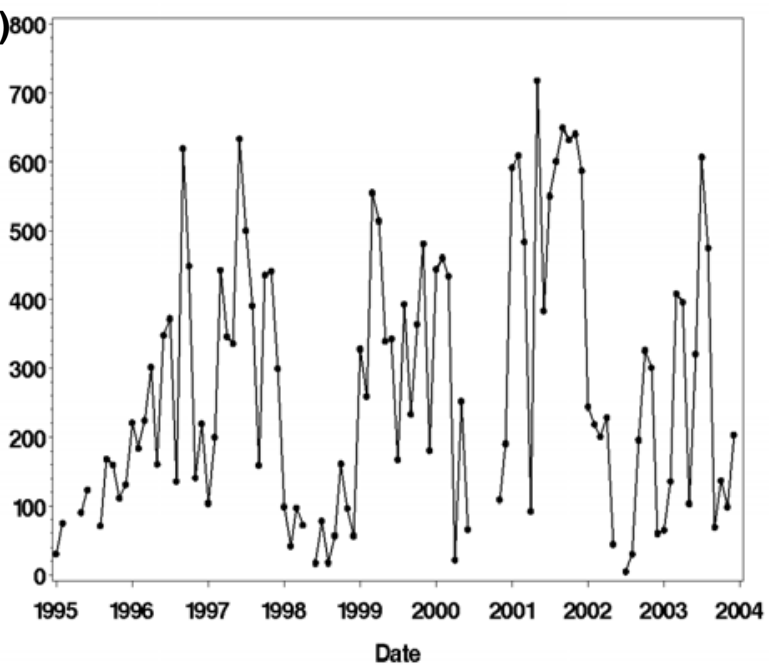

(c)

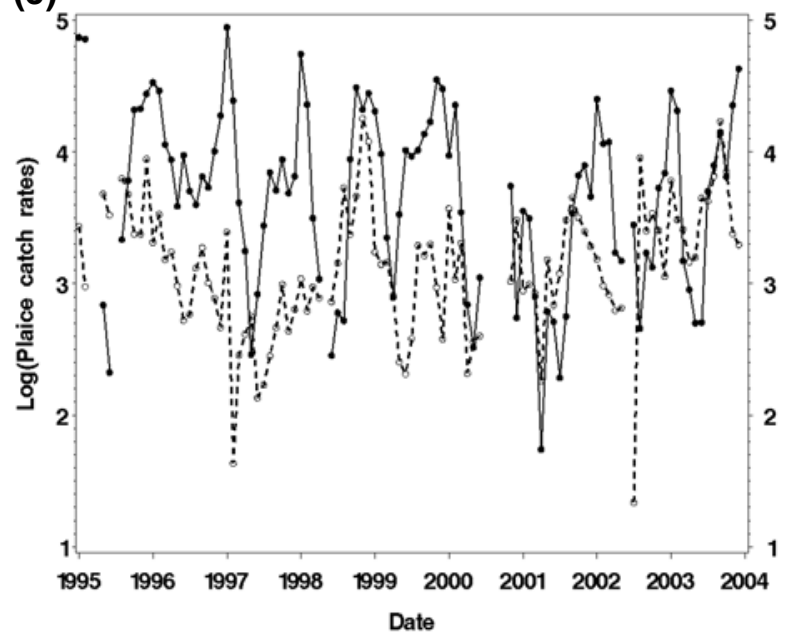

(d)

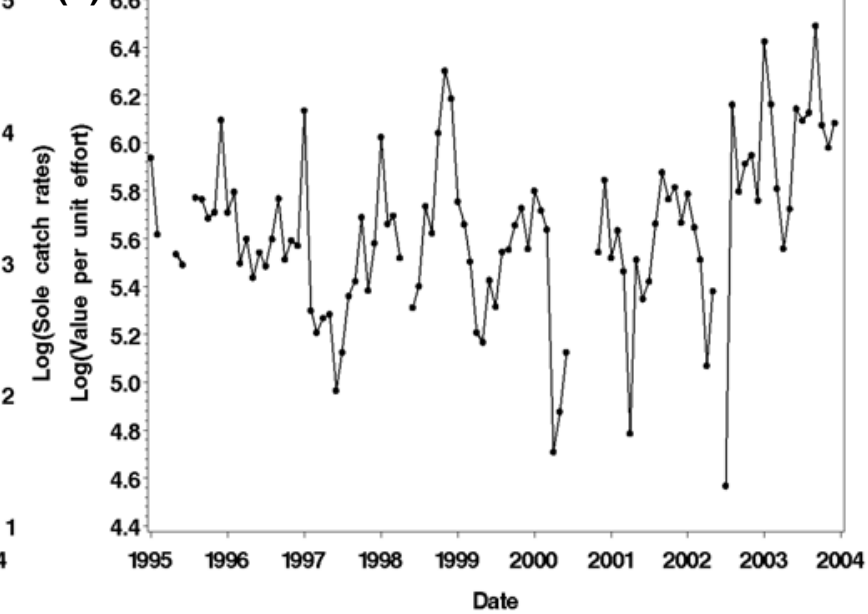


[Marchal et al. - Figure 3]

(a)

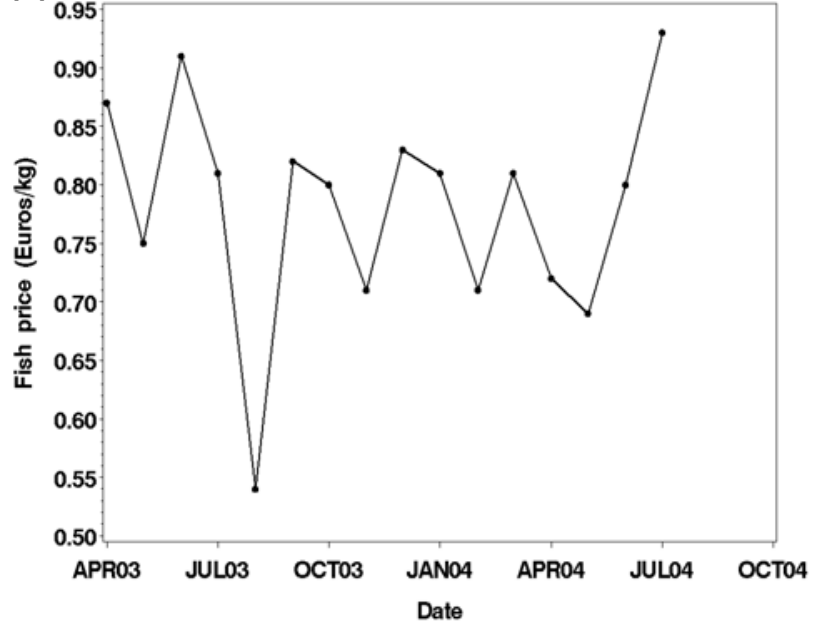

(c)

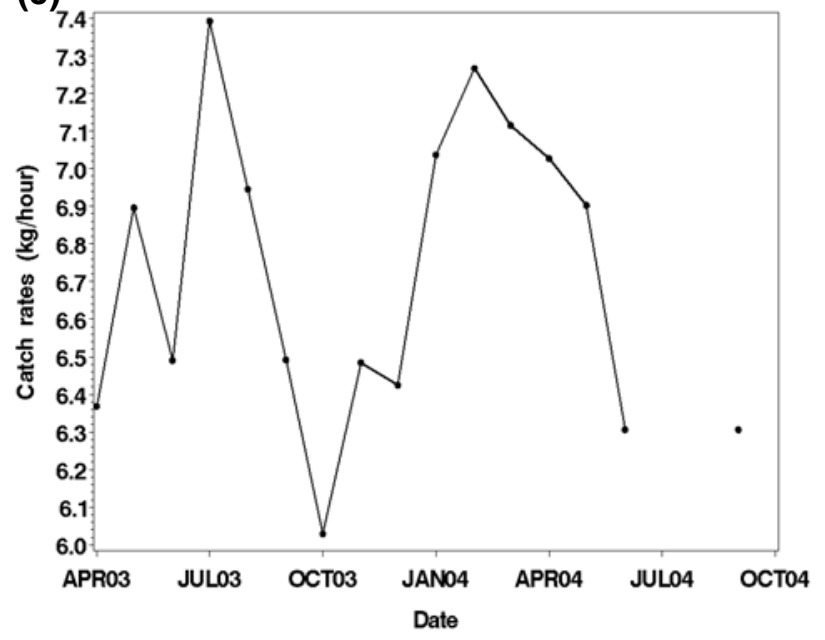

(b)

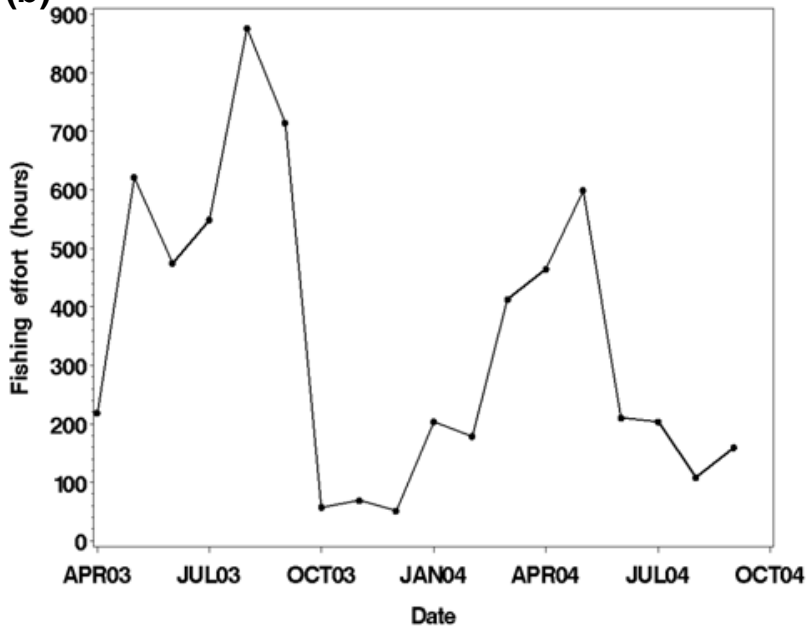


[Marchal et al. - Figure 4]

(a)

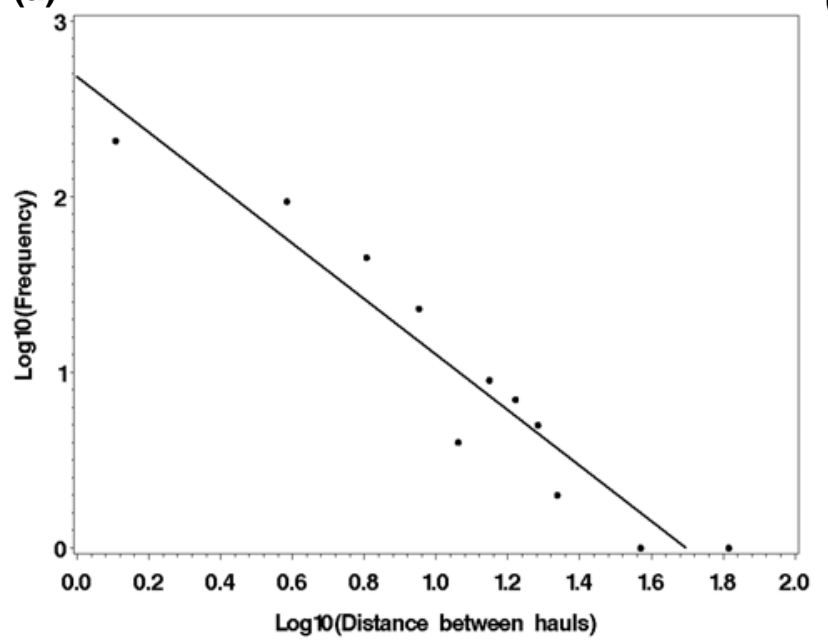

(b)

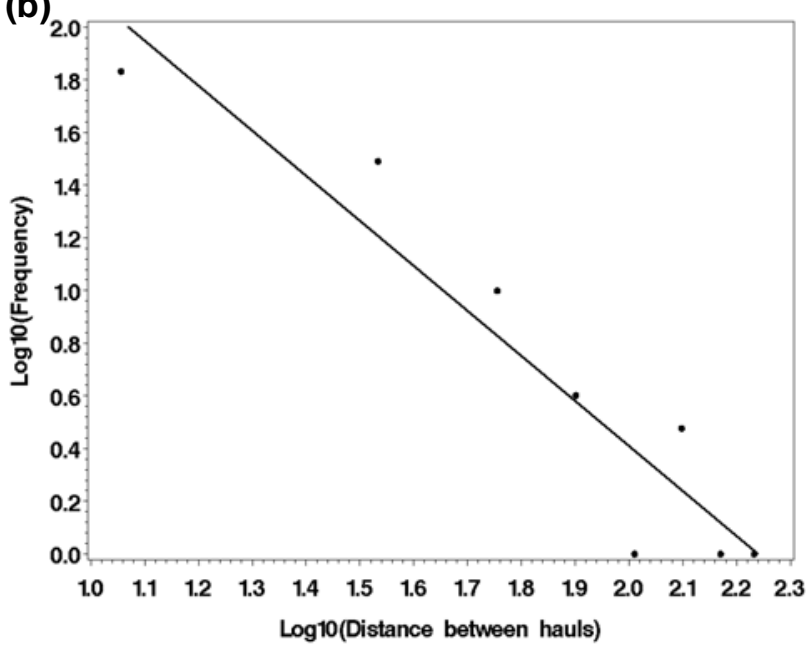


[Marchal et al. - Figure 5]
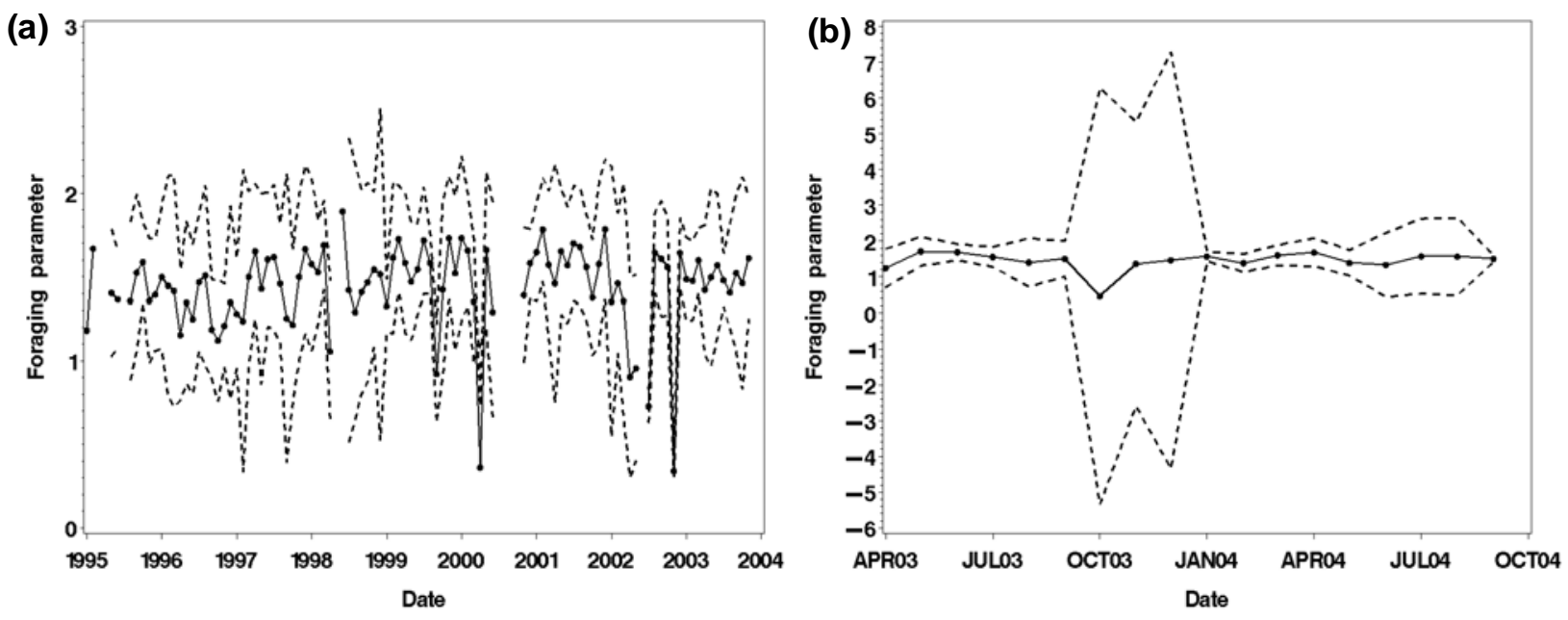
[Marchal et al. - Figure 6]

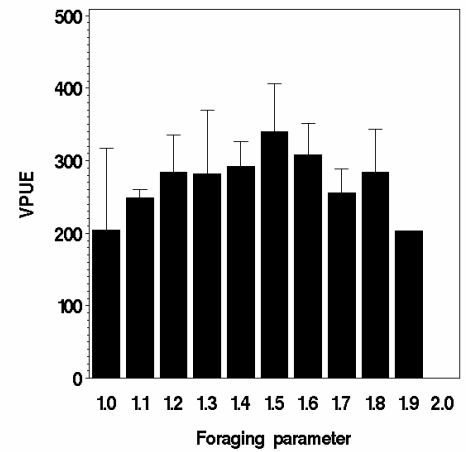


[Marchal et al. - Figure 7]

(a)

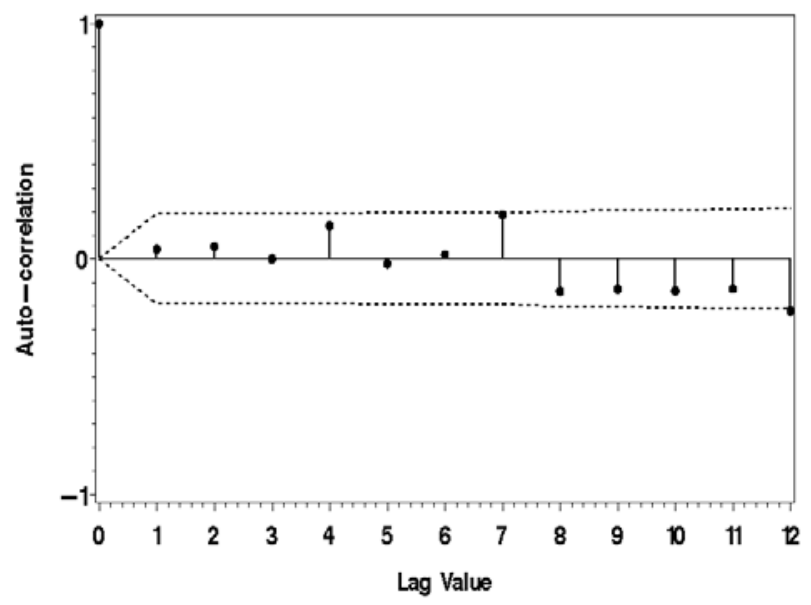

(b)
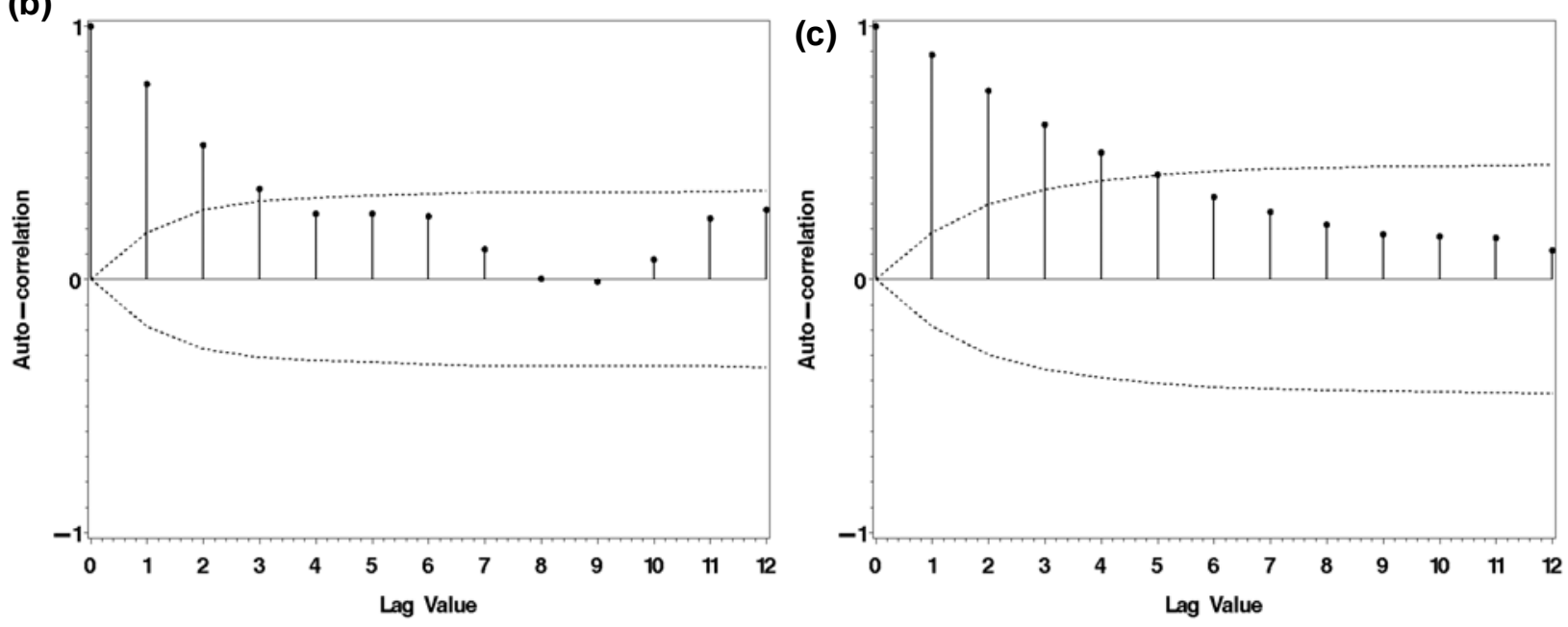

(d)
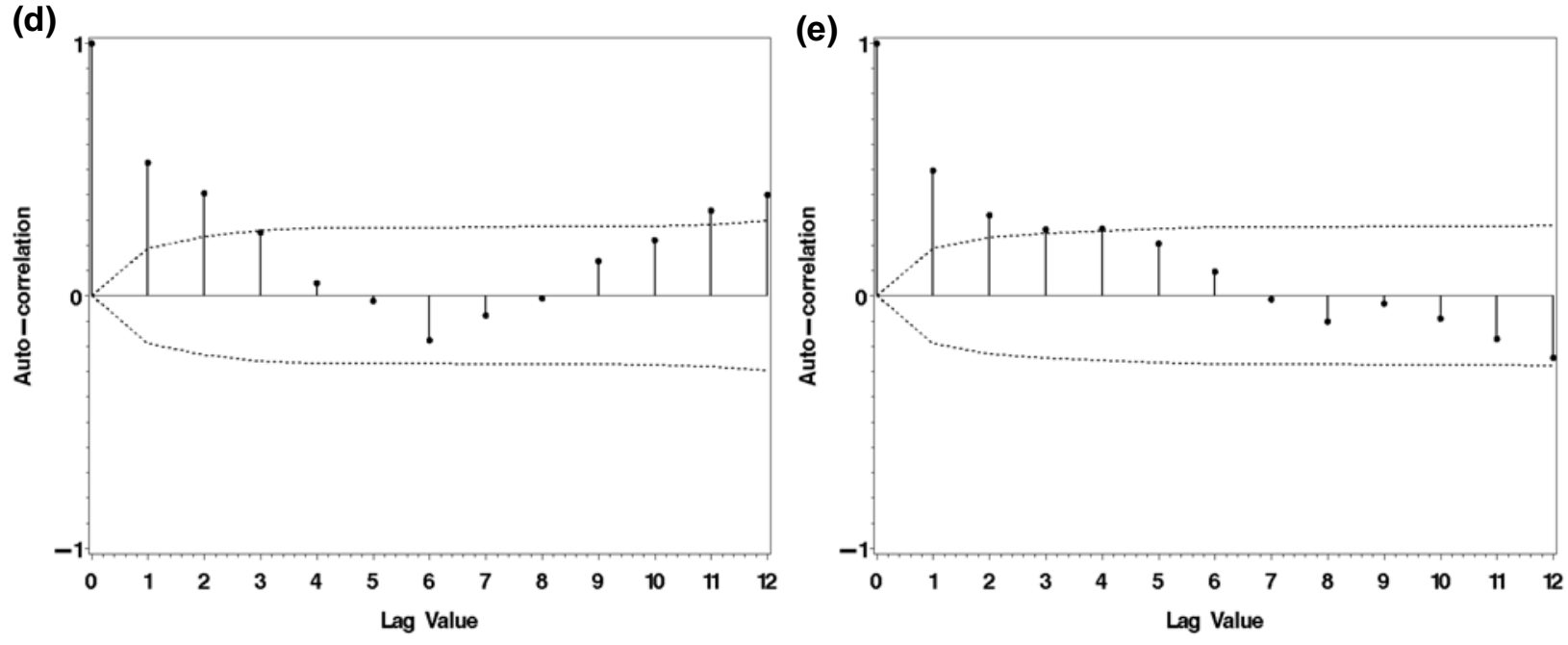
[Marchal et al. - Figure 8]

(a)

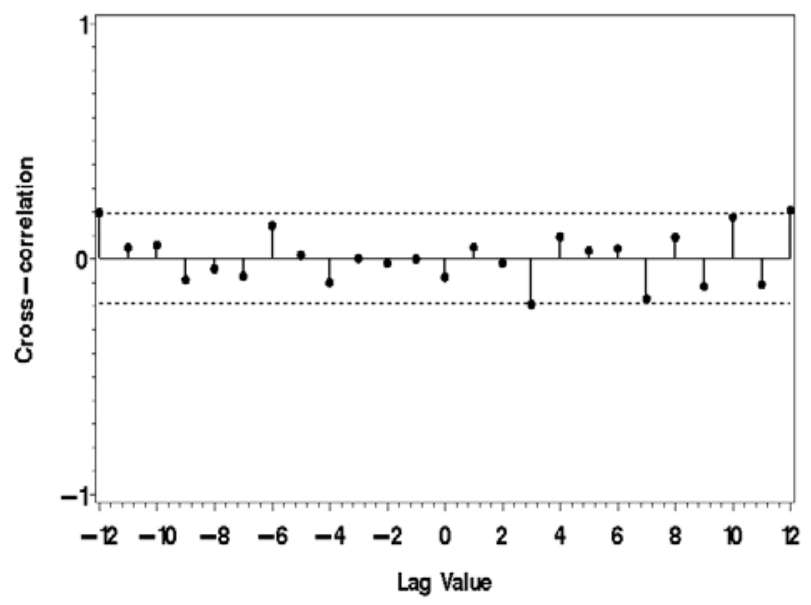

(c)

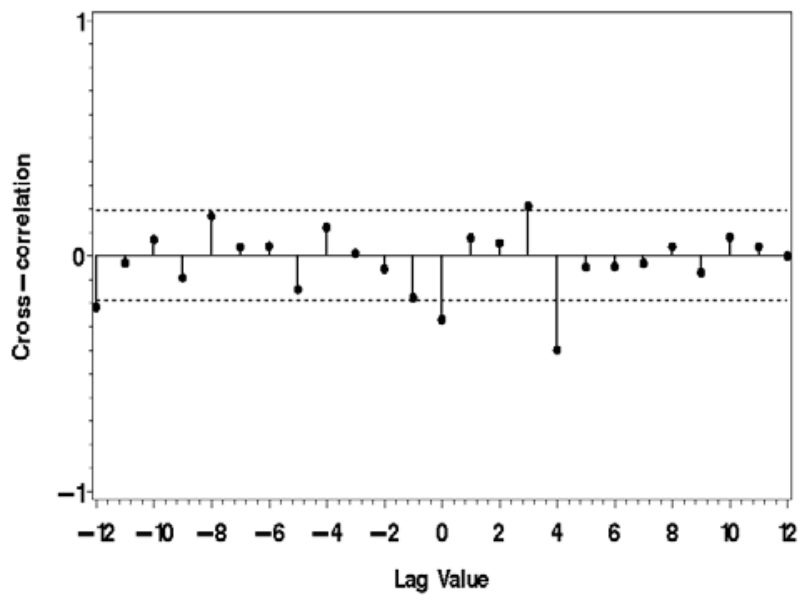

(b)

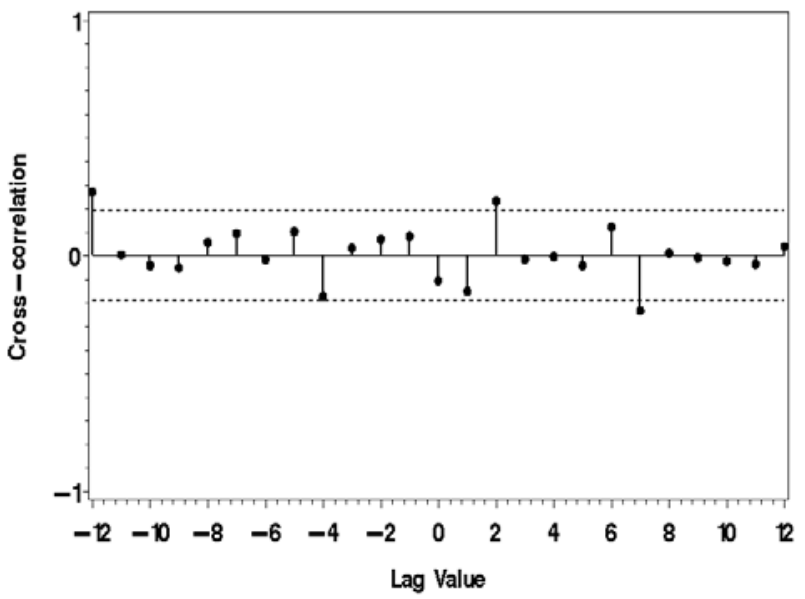

(d)

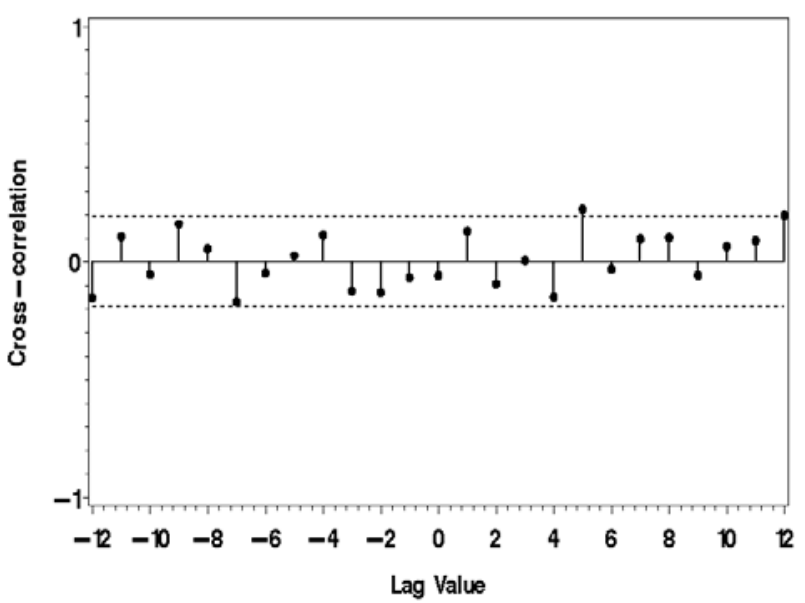


Table 1. Monthly number of vessels, fishing trips and fishing operations collected and used to provide landings and effort inputs to the present analysis; Mean (Minimum - Maximum).

\begin{tabular}{|l|l|l|l|l|}
\hline Fleet & Period investigated & No. vessels & No. trips & No. hauls \\
& & per month & per month & per month \\
\hline Dutch beam trawlers & January 1995 - December 2003 & $2(0-4)$ & $6(0-16)$ & $146(0-387)$ \\
\hline French otter trawlers & April 2003 - September 2004 & $3(1-4)$ & $6(3-13)$ & $68(10-185)$ \\
\hline
\end{tabular}


Table 2. Case study: Dutch large beam-trawlers. Parameters of the ARMA model used to pre-whiten the input time series of plaice (Pleuronectes platessa) prices, sole (Solea solea), Log(value per unit effort) and fishing effort.

\begin{tabular}{|l|l|l|l|l|l|}
\hline Type of parameter & Lag & Plaice prices & Sole prices & Log(VPUE) & Fishing effort \\
\hline Auto-regressive & 1 & 0.85 & 0.92 & 0.84 & 0.55 \\
\hline & 11 & & & 0.77 & \\
\hline Moving average & 12 & & & -0.61 & \\
\hline & 11 & & & 0.47 & \\
\hline & 12 & -0.29 & & 0.67 & \\
\hline
\end{tabular}

